\title{
Parent-Focused Change to Prevent Obesity in Preschoolers: Results from the KAN-DO Study
}

Truls Østbye, MD, PhD ${ }^{1,2}$, Katrina M. Krause, MA ${ }^{1}$, Marissa Stroo, BS ${ }^{1}$, Cheryl A. Lovelady, PhD, RD ${ }^{3}$, Kelly R. Evenson, $\mathrm{PhD}^{4}$, Bercedis L. Peterson, $\mathrm{PhD}^{5}$, Lori A. Bastian, MD, MPH ${ }^{6}$, Geeta K. Swamy, MD ${ }^{7}$, Deborah G. West, MS, RD, LDN ${ }^{3}$, Rebecca J.N. Brouwer, MS ${ }^{1}$, and Nancy L. Zucker, PhD ${ }^{8}$

${ }^{1}$ Department of Community and Family Medicine, Duke University Medical Center, Durham, NC

2Duke-NUS Graduate Medical School, Singapore

${ }^{3}$ Department of Nutrition, The University of North Carolina at Greensboro, Greensboro, NC

${ }^{4}$ Gillings School of Global Public Health, Department of Epidemiology, University of North Carolina at Chapel Hill, Chapel Hill, NC

${ }^{5}$ Department of Biostatistics and Bioinformatics, Duke University Medical Center, Durham, NC

${ }^{6}$ Department of Medicine, Duke University Medical Center, and Veteran's Affairs Medical Center, Durham, NC

${ }^{7}$ Department of Obstetrics and Gynecology, Duke University Medical Center, Durham, NC

${ }^{8}$ Department of Psychiatry and Behavioral Sciences, Duke University Medical Center, Durham, NC

\section{Abstract}

Objective-Present the immediate post-intervention results of Kids and Adults Now - Defeat Obesity!, a randomized controlled trial to enhance healthy lifestyle behaviors in motherpreschooler (2-5 years old) dyads in North Carolina (2007-2011). The outcomes include change from baseline in the child's diet, physical activity and weight, and in the mother's parenting behaviors, diet, physical activity, and weight.

Method-The intervention targeted parenting through maternal emotion regulation, home environment, feeding practices, and modeling of healthy behaviors. 400 Mother-child dyads were randomized.

Results-Mothers in the intervention arm, compared to the control arm, reduced instrumental feeding $(-0.24$ vs. $0.01, \mathrm{p}<0.001)$ and TV snacks $(-.069$ vs. $-0.24, \mathrm{p}=0.001)$. There were also improvements in emotional feeding $(\mathrm{p}=0.03)$, mother's sugary beverage $(\mathrm{p}=0.03)$ and fruit/ vegetable $(\mathrm{p}=0.04)$ intake, and dinners eaten in front of TV $(\mathrm{p}=0.01)$; these differences were not significant after adjustment for multiple comparisons.

\section{(c) 2012 Elsevier Inc. All rights reserved.}

Please send correspondence about this manuscript to: Professor Truls Østbye, Department of Community and Family Medicine, Duke University Medical Center 104006, Durham, NC 27710.

\section{Conflict of Interest}

The authors have no conflicts to report.

Publisher's Disclaimer: This is a PDF file of an unedited manuscript that has been accepted for publication. As a service to our customers we are providing this early version of the manuscript. The manuscript will undergo copyediting, typesetting, and review of the resulting proof before it is published in its final citable form. Please note that during the production process errors may be discovered which could affect the content, and all legal disclaimers that apply to the journal pertain. 
Conclusion-KAN-DO, designed to maximize the capacity of mothers as agents of change, improved several channels of maternal influence. There were no group differences in the primary outcomes, but differences were observed in the parenting and maternal outcomes and there were trends toward improvement in the preschoolers' diets. Long-term follow-up will address whether these short-term trends ultimately improve weight status.

\section{Keywords}

Obesity; randomized controlled trial; parenting; emotion regulation; physical activity; dietary intake

\section{BACKGROUND}

Having an overweight parent triples the likelihood that a child will be overweight, and at young ages is a stronger predictor of the child's future obesity risk than the child's own weight (Whitaker et al., 1997). Parents can be powerful agents of change since they influence a child's weight-related behaviors through direct interactions (e.g., the manner in which they feed their child or communicate about health behaviors), via role modeling of healthy behaviors (West et al., 2010), control of the home environment, and establishment of routines. Consequently, family-based interventions are recommended in childhood obesity treatment guidelines (Institue of Medicine, 2005; Barlow and Dietz, 1998) and may improve diet and physical activity in both children and adults (Golan et al., 1999; Wrotniak et al., 2004) Yet, interventions that specifically address parenting behaviors as a means to achieve these lifestyle goals remain limited. Furthermore, the most efficacious manner to support parents in their role remains unclear (Golley et al., 2011).

Most childhood obesity interventions to date have focused on teaching parents contingency management instruction and exercise/diet guidelines (Connelly et al., 2007; Golley et al., 2011) with less attention to the process of parenting (i.e. parenting style, the manner in which parents deliver behavioral directives) (Baumrind, 1978). In particular, an authoritative parenting style, (relative to more permissive or domineering parenting styles) has been associated with behaviors that may prevent obesity: increased physical activity (Schmitz et al., 2002), and less food stimuli in the home (Golan et al., 2006). Although general parenting style has not been consistently shown to be associated with feeding style (the manner in which parents feed their children), some particular feeding styles, such as using food as a reward (instrumental feeding) or to soothe negative emotions (emotional feeding), have been positively associated with child weight (Faith et al., 2004; Gerards et al., 2011).

To support healthy child weight and related behaviors, we are therefore warranted in targeting parenting and feeding styles. To develop an appropriate parenting style, we must first address the parent's own capacity to regulate his or her emotions: An important part of parenting style is whether parent can maintain a warm and consistent demeanor. Further, the ability to regulate one's emotional experience has broad self-regulatory effects beyond the domain of parenting: it is also associated with aberrant eating (e.g. binge and related emotional eating) and increased body mass. (Buckholdt et al., 2010) Thus, targeting emotion regulation may assist in the mother's ability to role model healthy behaviors. Especially given the demands of parenting young children and managing a household, instruction in emotion regulation, feeding style, and parenting style may help parents both role model and implement behavior change. (Blissett et al., 2010).

KAN-DO (Kids and Adults Now - Defeat Obesity!) is a randomized controlled trial of an intervention designed to promote healthy weight in preschool children. Mothers were recruited soon after the birth of a baby, which may be a critical period ("teachable moment") 
and offer a powerful motivational context for promoting behavior change (McBride et al., 2003). The intervention targeted the newborn's older sibling and the mother. The intervention material was delivered via mailed packets, a strategy successfully employed in other family-based interventions (Tilson et al., 2005). This method was chosen due to its potential for broad dissemination(Østbye et al., 2011).

KAN-DO was based on models of affective self-regulation (Bandura, 1986), and behavioral coaches trained mothers to both recognize and address emotional levels ("stepping down the emotional ladder") before communicating with the family. It also encouraged an authoritative parenting style (Birch and Fisher, 2000; Brody et al., 2002; Kim et al., 2003; Wills et al., 2003; Zucker et al., 2005) as a foundation for lifestyle change. The study's acronym reinforced this by encouraging Kind, Assertive, Neutral, Dependable, and Openminded (KAN-DO) parenting. Finally, the intervention taught portion control, healthy food options, exercise guidelines, and tips for behavior change in a family with young children (time constraints, fast food, day care, etc.). Consistent with social cognitive theory (Bandura, 1962; Bandura et al., 1963), parental role modeling was hypothesized to facilitate a mutual synergy of healthy mother-child behavior, and was thus emphasized throughout the intervention.

The primary outcomes for the overall KAN-DO study are change in child diet, physical activity, and sedentary behavior from baseline to immediately post-intervention, (hereafter referred to as follow-up 1), and child weight change from baseline to 22 months postbaseline (follow-up 2). Secondary outcomes and potential mediating factors include change in parenting behaviors, mother's dietary intake and physical activity, and mother and child weight (at follow-up 1). This manuscript presents follow-up 1 primary and secondary outcomes.

\section{MATERIALS AND METHODS}

\section{Study population, recruitment, and randomization}

The target population was postpartum women who were overweight or obese (National Institutes of Health, 1998) prior to pregnancy and their children aged 2-5 years, in the Triangle and Triad regions of North Carolina. Women were primarily identified from state birth certificates and screened for eligibility at $2-6$ months postpartum (Østbye et al., 2011). To be eligible, mothers had: a preschooler aged $2-5$ years, self-reported pre-pregnancy (and measured postpartum) body mass index (BMI) $\geq 25 \mathrm{~kg} / \mathrm{m}^{2}$, no medical conditions preventing daily physical activity, English literacy, regular telephone access, and be $\geq 18$ years of age.

Eligible and interested dyads attended a baseline assessment. After written informed consent, measurements were taken including standardized height and weight of mother and preschooler. Four hundred dyads were randomized (November 2007 - October 2009) with equal allocation to intervention and control arms via permuted 8-block randomization. KAN-DO was approved by the Institutional Review Boards of the Duke University Health System and UNCG and registered with Clinicaltrials.gov (NCT00563264). The design and rationale have been described in detail (Østbye et al., 2011).

\section{Intervention (Figure 1)}

Participants in the intervention arm received 8 monthly mailed interactive kits, followed each month by a 20-30 minute telephone coaching session using motivational interviewing techniques. Kits included child activities and incentives reinforcing the month's topic (e.g., a rewards chart, yoga mat, pedometer, portion plate). 
The intervention targeted the dyad's healthy weight via instruction in parenting styles and skills, techniques for stress management (including emotion regulation), and education about healthy behaviors. Parenting skill instruction emphasized 1) an authoritative parenting style, 2) routines for sleep and mealtimes, 3) a supportive home environment, 4) role modeling of healthy eating and physical activity, and 5) improvement of feeding style. Education about healthy behavior changes in the dyad targeted: decreased intake of sugary drinks and fast food, increased fruit and vegetable consumption, meals prepared at home, moderate-to-vigorous physical activity (MVPA), and decreased sedentary behavior.

Coaching calls reviewed information in the module and addressed motivation, self-efficacy, and barriers to change. Consistent with motivational interviewing principles (Miller and Rollnick, 2002), the coaches used reflective listening to elicit goals for behavior changes and stress management. The intervention also included one semi-structured group session, where the study coaches and nutritionist reinforced content from the family kits and set aside time for role play and group discussion. A healthy meal and free child care were provided.

Control arm participants received monthly newsletters emphasizing pre-reading skills (www.rif.org). Retention was encouraged by monetary incentives (up to $\$ 100$ for completion of all assessments). Participants were also asked to provide a locator contact in case they moved or changed phone numbers.

\section{Measures}

Assessments were collected at study entry ("baseline" - 2-6 months postpartum) and postintervention ("follow-up 1") using validated scales (except where noted). Emotion regulation was measured using the competency subscale of the Parenting Stress Index (PSI) (Abidin, 2004), and parental feeding practices using the Parental Feeding Style Questionnaire (Wardle et al., 2002). The instrumental feeding ("I reward ... with something to eat when s/he is well behaved"), emotional feeding ("I give ... something to eat to make $\mathrm{him} /$ her feel better when s/he is worried"), control ("I decide the times when ... eats his/her meals"), and encouragement ("I encourage ... to eat a wide variety of foods") subscales were used to measure change in these behaviors. Home environment changes targeted in the intervention included regular family meals, measured by the Family Meals Questionnaire (Neumark-Sztainer et al., 2004), television viewing habits (Hesketh et al., 2007), and healthy food availability ("How often do you have healthy snacks/vegetables/fruits in the home?").

The mother's daily total energy intake and percent of energy from fat were measured twice following the study visit via a telephone-administered, multiple-pass, 24-hour dietary recall using the Nutrition Data System for Research (2009) (Jonnalagadda et al., 2000; Tran et al., 2000). Mothers reported daily intake of sugary beverages (Dubois et al., 2007; Malik et al., 2006), fast food servings (Bowman et al., 2004; Bowman and Vinyard, 2004), fruits and vegetables (Alinia et al., 2009; Ledoux et al., 2010) for both themselves and their preschoolers; these foods were targets of the intervention given their documented link to obesity, therefore we measured the intake to determine intervention effectiveness.

Physical activity was measured in both preschooler and mother using Actical accelerometers (Klippel and Heil, 2003; Puyau et al., 2002; Puyau et al., 2004) (model \#198-0200, MiniMitter Co. Inc., Bend, Oregon). Data were summarized as minutes of moderate to vigorous physical activity (MVPA) and sedentary behavior. For children, MVPA was defined as $\geq$ 715 counts/15 second epoch (Pfeiffer et al., 2006), sedentary time as $<12$ counts/15 second epoch (Evenson et al., 2008), with more than 20 consecutive minutes of zeroes constituting non-wear time. For mothers, MVPA was defined as $\geq 1535$ counts/ 1 minute epoch (Colley and Tremblay, 2011), sedentary time as $\$ 50$ counts/1 minute epoch, with 60 consecutive 
minutes of zero counts constituting non-wear time. Minimum wear time was set at 6 hours/ day, and participants must have contributed at least 3 valid days (including a weekend) to be included in the analysis. Time spent watching TV (for both mother and preschooler) was also reported.

Height, in minimal street clothing without shoes was obtained using a Seca portable stadiometer and weight using a Tanita BWB-800 scale. Four percent $(n=13)$ of weights at follow-up were self-reported (participant moved away or otherwise unavailable); either measured by a doctor or collected from another calibrated scale $(n=7)$ or home scale $(n=6)$. Child BMI z-score was calculated to measure relative weight adjusted for age and sex (CDC, 2009).

Intervention participation was indicated by attendance at the group session and completion of coaching calls. Extent and quality of involvement with family kit activities was assessed at calls and through returned postcards (5 questions querying kit content and engagement with child activity; participants were given $\$ 5$ for each returned postcard).

\section{Statistical analysis}

Mean differences between study arms in change from baseline to post-intervention were assessed on 25 outcomes. Based on 200 participants per arm, the study had $90 \%$ power when the true standardized mean arm difference was 0.374. According to Cohen (1988), this effect size is between "small" and "medium". The logistic regression model was used to test for difference between study arms in number of daily servings of fruits and vegetables ( 25 vs. $<5)$ at post-intervention. For all other outcomes, t-tests from general linear models were used to test for mean differences between study arms. Baseline value was used as a covariate in all models. While only participants with follow-up data were used in these analyses, sensitivity analyses were also conducted, in which missing follow-up measurements were imputed to their baseline values.

Given the multiple comparisons presented in the study, the Benjamini-Hochberg (Benjamini and Hochberg, 1995) procedure was used to control the overall 2-sided alpha level at 0.05 . Specifically, letting "rank" be the ascending rank order of the 25 observed p-values from highest $\mathrm{p}$-value to lowest, the assigned alpha levels were $0.05^{*}(\mathrm{rank} / 25)$. Moving from lower to higher rank, as soon as a test was found to be non-significant, all further tests of higher rank were also declared non-significant.

\section{RESULTS}

\section{Participant disposition}

Of approximately 40,000 women initially identified through state birth records, 400 dyads were randomized into the study (Figure 2). Of these, 308 completed first follow-up 1 assessments (156: intervention arm; 152: control arm) and were included in these analyses. The excluded 92 women either did not complete follow-up assessments $(n=6)$, or were lost to follow-up (refused to participate ( $n=11)$, could not be reached $(n=50)$, did not show-up for scheduled visit $(\mathrm{n}=25))$.

\section{Baseline characteristics (Table 1)}

About $60 \%$ of enrolled mothers were obese (BMI $\geq 30 \mathrm{~kg} / \mathrm{m}^{2}$ ), and $25 \%$ of preschoolers were already overweight or obese (BMI $\geq 85^{\text {th }}$ percentile). Seventy-five percent of mothers were white, and $86 \%$ were married. Almost $70 \%$ had a college or postgraduate education and $57 \%$ had a yearly household income above $\$ 60,000$. These data are for the full baseline sample $(n=400)$. The characteristics of the analysis sample were very similar, but those who 
completed follow-up were somewhat more likely to be older, married or partnered, more educated, and more affluent than non-completers (data not shown). There were no notable differences between the study arms at baseline.

\section{Follow-up assessments post-intervention}

Sixty-eight percent of all participants $(\mathrm{n}=273)$ completed all follow-up 1 measures. Of these, 19 mothers were pregnant again and 6 had delivered a new baby since baseline; these 25 women were excluded from analyses of mother's dietary intake, physical activity and weight. Figure 2 shows the number of participants available for analyses of the different outcomes.

\section{Participation}

All 200 participants in the intervention arm received the 8 family kit materials, and 188 had at least one intervention contact. They completed a mean of 4.1 of 8 coaching calls, returned 3.3 of 8 postcards, and $46 \%$ attended the group class. Participation in any of the intervention components was higher, (but not significantly so), among women who were older, white, married, and more educated. Participation did not differ by BMI (data not shown).

\section{Change in parenting, home environment, and modeled behaviors (Tables $2 \& 3$ )}

In children (Table 2), there were small differences between study arms in dietary intake, but these differences were not significant (sugary beverages, $\mathrm{p}=0.13$; fast food, $\mathrm{p}=0.26$; fruits and vegetables, $\mathrm{p}=0.16)$. There were no such differences in physical activity $(\mathrm{p}=0.41)$ or sedentary behavior $(\mathrm{p}=0.50)$. Change in weight among children was not statistically different between arms $(\mathrm{p}=0.63)$.

Mothers (Table 3) in the intervention arm showed an increase in self-rated parenting competency (a measure of emotion regulation) compared to those in the control arm (0.49 vs. -0.09$)$, although this difference was not statistically significant $(\mathrm{p}=0.16)$. Mothers in the intervention arm decreased instrumental feeding (using food as a reward) -0.24 vs. 0.01 ; $\mathrm{p} \unlhd 0.001$ ) and emotional feeding ( -0.09 vs. $-0.03 ; \mathrm{p}=0.03$ ). Child's dinners and snacks eaten in front of the TV decreased more in the intervention arm than in the control arm $(-0.69$ vs. $-0.20 ; \mathrm{p}=0.01$ for dinners, -0.69 vs. $-0.24 ; \mathrm{p}=0.001$ for snacks). The availability of healthy food in the home improved slightly more in the intervention arm ( 0.13 vs. $0.05 ; \mathrm{p}=0.09)$. When using the Benjamini-Hochberg procedure to control for multiple comparisons, two of the results (instrumental feeding and snacks in front of the TV) remained significant ( $p$ value $<$ Benjamini-Hochberg alpha level). The results of the sensitivity analyses (not shown), in which missing follow-up measurements were imputed to their baseline values, were consistent with the results presented.

In regard to role modeling, mothers in the intervention arm reduced sugary beverage intake more than mothers in the control arm $(-5.78 \mathrm{oz}$ vs. $-2.24 \mathrm{oz} ; \mathrm{p}=0.03)$, and the percentage eating 5 or more servings of fruits and vegetables a day increased (by $8.4 \%$ in intervention arm vs. $0.0 \%$ in the control arm; $\mathrm{p}=0.04$ ). Sedentary time decreased slightly among controls, but the arm difference was not significantly when controlled for wear time. Change in maternal weight was not statistically different between arms, and there were no other significant differences in mothers' behaviors.

In exploratory analyses, the effect of participation on mother's and child's weight change was assessed. Mothers who completed at least half of the possible 16 intervention contacts (completed coaching calls and returned postcards) showed a greater mean change in BMI than those who did not $(-0.85$ vs. $-0.07 ; \mathrm{p}=0.04)$. 


\section{DISCUSSION}

Making changes to dietary intake and physical activity is challenging at any time; instituting such changes in a home environment with multiple young children may be particularly overwhelming. Mothers of multiple children may face challenges in trying to change unhealthy behaviors and routines that may already be established with older children. Mothers with at least two children were selected due to their relative vulnerability, and the fact that they are often not the targets of intervention studies. While first-time mothers receive increased attention and support from family, friends, and healthcare providers, the degree of support may be significantly reduced for mothers who might be viewed as "experienced." Given the increased demands of multiple children, convenient strategies such as resorting to fast food meals and using food as a reward may be increasingly likely, while the capacity to attend a live group-based session increasingly challenging. While these considerations added to the uniqueness of the current intervention, it may have decreased overall effectiveness.

Despite this challenging context, KAN-DO resulted in significant improvements in feeding practices, maternal dietary intake (greater reduction in sugary beverage intake and increased consumption of fruit and vegetables), and changes in the home environment (fewer dinners and snacks eaten in front of the television). KAN-DO is the first study demonstrating that changes to parenting behaviors (feeding practices) can be made via a mailed intervention. In the children statistically significant improvements in health behaviors and BMI z-score were not observed. Positive trends were seen in child dietary intake, but not sedentary behaviors, and amount of physical activity, and BMI z-score. These results may be due to limited sample size, or measurement error.

In KAN-DO, mothers were provided with power tools to build skills in emotion regulation. The intervention emphasized that a mother's attempts to improve healthy lifestyles in her home can be more effective when she is better able to adopt and model these behaviors herself (Jahnke and Warschburger, 2008; Snoek et al., 2007). Empirical evidence supports that, in general, individuals are more accurate at perceiving the motivations of others when they are more accurate at perceiving their own motivations, including emotional experience (Prkachin et al., 2009). From this perspective, the observed reductions in emotional feeding may reflect that mothers' improvement in their ability to recognize their own emotions may have helped them differentiate hunger from emotion in their children. Such changes may establish a foundation for improved self-regulation in the child. Further, when fed in response to emotional stimuli rather than to biological hunger, children may learn to confuse physiological responses of emotion (e.g. "butterflies in the stomach") with hunger. Future research should more systematically examine the impact of changes in emotional feeding on the development of self-regulatory capacities in children.

Reductions in instrumental feeding may also reflect improvements in the mother's ability to manage her child's behavior without resorting to food rewards. Food is inherently rewarding as it satiates biological hunger (van den Bos and de Ridder, 2006). Thus, when the mother instrumentally feeds her child (i.e., offers food as a reward), she increases the value of something already perceived to be valuable. Whether reductions in instrumental feeding can impact responsivity to food cues in vulnerable children is also an interesting area for further study.

Through role modeling, changes in maternal behavior may likewise have "downstream" effects on child behavior. It is easier to develop healthy behaviors than to alter unhealthy habits. Thus, it is promising that mothers decreased consumption of sugar-sweetened beverages and increased intake of fruits and vegetables. Positive changes in maternal 
behavior imply that the child is exposed to adaptive behavior that can guide his or her own decisions, and unhealthy foods may be less available in the home (Golan, 2006).

Prior interventions differ in several respects from KAN-DO in terms of developmental stage of the study participants, mode of intervention delivery, and sample size. For example, the UK Families for Health trial (Robertson et al., 2008) addressed parenting and emotional regulation in older children, via live parallel groups of parents and adolescents (total sample only 27 individuals). Similar to the current study, improvements were observed in exposure to unhealthy foods, and, while not directly comparable to KAN-DO, improvements were also seen in child quality of life, sedentary behavior, and parent mental health. Golley et. al. (2007) demonstrated the value of parenting skills in the context of an obesity intervention for 5-9 year olds $(\mathrm{n}=110)$. The parenting skills intervention resulted in a 5\% reduction in BMI.

\section{Strengths and Limitations}

KAN-DO's strengths include the relatively large sample size, the unique developmental stage that was targeted, and the racial and economic diversity of the sample. Despite this diversity, the women who enrolled tended to be highly educated, and a high proportion were married. The mode of delivery provided insights into the amount and intensity of intervention needed to promote behavior change. Yet, the design strategy may have limited the impact of the intervention as change in important domains of health behavior could not be shown. The standardized assessment was comprehensive; this was both a strength and a weakness: while it attempted to capture a broad spectrum of factors that may evidence change, it also resulted in a large number of statistical comparisons, and potentially high participant burden. The findings may also be limited by the fact that many outcomes are based on self-reported measures.

\section{Implications \& Conclusions}

While parents have long been regarded as critical in the prevention of childhood obesity, the best way to integrate parents and facilitate dyadic change remains unclear. The KAN-DO intervention builds on the small, but growing, body of work incorporating parenting practices into obesity interventions.

KAN-DO was an ambitious trial; women at a challenging time in their lives, soon after the birth of a new baby, were approached to take part in a fairly complex intervention together with their preschoolers. Its development was guided by a desire to find the type and intensity of an intervention that is comprehensive, but not so elaborate as to prohibit dissemination. Thus, the resulting intervention was designed to be reasonable for mothers of young children. It appears to have been appropriate as evidenced by the high level of interest; however, enrollment, as well as full participation among those enrolled, was difficult, especially for women at lower socioeconomic levels, who may be most in need of intervention. This is consistent with the few earlier studies of public health interventions targeting similar at-risk dyads (Golley et al., 2007; Robertson et al., 2008; West et al., 2010). Future studies should investigate alternative methods of delivery (e.g. mobile technologies) to assist new mothers in getting the ongoing support and information they need. Yet, it is still plausible that the intervention dose received in KAN-DO, and the resulting improvements in feeding practices, maternal dietary intake, and home environment will lead to a healthier future for these young children.

\section{Acknowledgments}

This study was funded by a grant from the National Institute of Health (NIH), National Institute of Diabetes, Digestive and Kidney Diseases (R01-DK-07549). Dr. Zucker was supported by grant 1-K23-MH-070-418-01. 
Thanks to Anne Bowman, LaCrystal Strong, Gina Moening, and Erin Street for help with collection and analysis of dietary intake data, to Dr. Bernard Fuemmeler for helpful advice, to Jessica Revels and Hannah Harvey for delivery of the KAN-DO intervention, to Diane Glifford for database development, and to Nedenia Parker, Linda Tymann, Karen Sailstad, and DeLana Orr for help with data collection and recruiting. The study was approved by the Institutional Review Board of Duke University Health System on 06/14/2008 and is registered with Clinicaltrials.gov (NCT00563264). The content is solely the responsibility of the authors and does not necessarily represent the official views of the NIH.

\section{References}

Abidin, RR. Parenting Stress Index. 3. Psychological Assessment Resources, Inc; Lutz, FL: 2004.

Alinia S, Hels O, Tetens I. The potential association between fruit intake and body weight - a review. Obesity Reviews. 2009; 10:639-47. [PubMed: 19413705]

Bandura, A. Social learning through imitation. Jones, MR., editor. University of Nebrask Press; Lincoln: 1962.

Bandura, A. Social Foundations of Thought and Action: A Social Cognitive Theory. Prentis Hall, Inc; Englewood Cliffs, NJ: 1986.

Bandura A, Ross D, Ross SA. Vicarious reinforcement and imitative learning. The Journal of Abnormal and Social Psychology. 1963; 67:601-07.

Barlow SE, Dietz WH. Obesity Evaluation and Treatment: Expert Committee Recommendations. Pediatrics. 1998; 102:e29. [PubMed: 9724677]

Baumrind D. Parental Disciplinary Patterns and Social Competence in Children. Youth \& Society. 1978; 9:239-67.

Benjamini Y, Hochberg Y. Controlling the False Discovery Rate: A Practical and Powerful Approach to Multiple Testing. Journal of the Royal Statistical Society Series B (Methodological). 1995; 57:289-300.

Birch LL, Fisher JO. Mothers' child-feeding practices influence daughters' eating and weight. The American Journal of Clinical Nutrition. 2000; 71:1054-61. [PubMed: 10799366]

Blissett J, Haycraft E, Farrow C. Inducing preschool children's emotional eating: relations with parental feeding practices. The American Journal of Clinical Nutrition. 2010; 92:359-65. [PubMed: 20534744]

Bowman SA, Gortmaker SL, Ebbeling CB, Pereira MA, Ludwig DS. Effects of fast-food consumption on energy intake and diet quality among children in a national household survey. Pediatrics. 2004; 113:112-18. [PubMed: 14702458]

Bowman SA, Vinyard BT. Fast Food Consumption of U.S. Adults: Impact on Energy and Nutrient Intakes and Overweight Status. J Am Coll Nutr. 2004; 23:163-68. [PubMed: 15047683]

Brody GH, Dorsey S, Forehand R, Armistead L. Unique and Protective Contributions of Parenting and Classroom Processes to the Adjustment of African American Children Living in Single-Parent Families. Child Development. 2002; 73:274-86. [PubMed: 14717257]

Buckholdt KE, Parra GR, Jobe-Shields L. Emotion dysregulation as a mechanism through which parental magnification of sadness increases risk for binge eating and limited control of eating behaviors. Eating Behaviors. 2010; 11:122-26. [PubMed: 20188297]

Centers for Disease Control. CDC. Z-score Data Files. 2009.

Cohen, J. Statistical power analysis for the behavioral sciences. Lawrence Erlbaum Associates; Hillsdale NJ: 1988.

Colley RC, Tremblay MS. Moderate and vigorous physical activity intensity cut-points for the Actical accelerometer. Journal of Sports Sciences. 2011; 29:783-89. [PubMed: 21424979]

Connelly JB, Duaso MJ, Butler G. A systematic review of controlled trials of interventions to prevent childhood obesity and overweight: A realistic synthesis of the evidence. Public Health. 2007; 121:510-17. [PubMed: 17467752]

Dubois L, Farmer A, Girard M, Peterson K. Regular Sugar-Sweetened Beverage Consumption between Meals Increases Risk of Overweight among Preschool-Aged Children. Journal of the American Dietetic Association. 2007; 107:924-34. [PubMed: 17524711]

Evenson K, Cattellier D, Gill K, Ondrak K, McMurray R. Calibration of two objective measures of physical activity for children. Journal of Sports Sciences. 2008; 26:1557-65. [PubMed: 18949660] 
Faith MS, Berkowitz RI, Stallings VA, Kerns J, Storey M, Stunkard AJ. Parental Feeding Attitudes and Styles and Child Body Mass Index: Prospective Analysis of a Gene-Environment Interaction. Pediatrics. 2004; 114:e429-e36. [PubMed: 15466068]

Gerards SMPL, Sleddens EFC, Dagnelie PC, de Vries NK, Kremers SPJ. Interventions addressing general parenting to prevent or treat childhood obesity. International Journal of Pediatric Obesity. 2011; 6:e28-e45. [PubMed: 21657977]

Golan M. Parents as agents of change in childhood obesity - from research to practice. International Journal of Pediatric Obesity. 2006; 1:66-76. [PubMed: 17907317]

Golan M, Kaufman V, Shahar DR. Childhood obesity treatment: targeting parents exclusively v. parents and children. British Journal of Nutrition. 2006; 95:1008-15. [PubMed: 16611394]

Golan M, Weizman A, Fainaru M. Impact of Treatment for Childhood Obesity on Parental Risk Factors for Cardiovascular Disease. Preventive Medicine. 1999; 29:519-26. [PubMed: 10600433]

Golley RK, Hendrie GA, Slater A, Corsini N. Interventions that involve parents to improve children's weight-related nutrition intake and activity patterns - what nutrition and activity targets and behaviour change techniques are associated with intervention effectiveness? Obesity Reviews. 2011; 12:114-30. [PubMed: 20406416]

Golley RK, Magarey AM, Baur LA, Steinbeck KS, Daniels LA. Twelve-Month Effectiveness of a Parent-led, Family-Focused Weight-Management Program for Prepubertal Children: A Randomized, Controlled Trial. Pediatrics. 2007; 119:517-25. [PubMed: 17332205]

Hesketh K, Ball K, Crawford D, Campbell K, Salmon J. Mediators of the Relationship Between Maternal Education and Children's TV Viewing. American Journal of Preventive Medicine. 2007; 33:41-47. [PubMed: 17572310]

Jahnke DL, Warschburger PA. Familial Transmission of Eating Behaviors in Preschool-aged Children. Obesity. 2008; 16:1821-25. [PubMed: 18483480]

Jonnalagadda SS, Mitchell DC, Smiciklas-Wright H, Meaker KB, Heel NV, Karmally W, Ershow AG, Kris-Etherton PM. Accuracy of Energy Intake Data Estimated by a Multiplepass, 24-hour Dietary Recall Technique. Journal of the American Dietetic Association. 2000; 100:303-11. [PubMed: 10719403]

Kim IJ, Ge X, Brody GH, Conger RD, Gibbons FX, Simons RL. Parenting Behaviors and the Occurrence and Co-Occurrence of Depressive Symptoms and Conduct Problems Among African American Children. Journal of Family Psychology. 2003; 17:571-83. [PubMed: 14640806]

Klippel NJ, Heil DP. Validation of Energy Expenditure Prediction Algorithms in Adults Using the Actical Electronic Activity Monitor. Medicine \& Science in Sports \& Exercise. 2003; 35:S284.

Ledoux TA, Hingle MD, Baranowski T. Relationship of fruit and vegetable intake with adiposity: a systematic review. Obesity Reviews. 2010:e143-50.

Malik VS, Schulze MB, Hu FB. Intake of sugar-sweetened beverages and weight gain: a systematic review. The American Journal of Clinical Nutrition. 2006; 84:274-88. [PubMed: 16895873]

McBride CM, Emmons KM, Lipkus IM. Understanding the potential of teachable moments: the case of smoking cessation. Health Education Research. 2003; 18:156-70. [PubMed: 12729175]

Medicine Io. Institute of Medicine. Preventing Childhood Obesity: Health in the Balance. National Academies Press; Washington, D.C: 2005.

Miller, WR.; Rollnick, SP. Motivational Interviewing: preparing people for change. 2. The Guilford Press; New York: 2002.

NHLBI Obesity Task Force. Obes Res. 1998/11/14. 1998. Clinical Guidelines on the Identification, Evaluation, and Treatment of Overweight and Obesity in Adults--The Evidence Report. National Institutes of Health; p. 51S-209S.

Neumark-Sztainer D, Wall M, Story M, Fulkerson JA. Are family meal patterns associated with disordered eating behaviors among adolescents? Journal of Adolescent Health. 2004; 35:350-59. [PubMed: 15488428]

Østbye T, Zucker NL, Krause KM, Lovelady CA, Evenson KR, Peterson BL, Bastian LA, Swamy GK, West DG, et al. Kids and Adults Now! Defeat Obesity (KAN-DO): Rationale, design and baseline characteristics. Contemporary Clinical Trials. 2011; 32:461-69. [PubMed: 21300177] 
Pfeiffer KA, McIver KL, Dowda M, Almeida MJCA, Pate RR. Validation and Calibration of the Actical Accelerometer in Preschool Children. Medicine \& Science in Sports \& Exercise. 2006; 38:152-57. [PubMed: 16394968]

Puyau MR, Adolph AL, Vohra FA, Butte NF. Validation and Calibration of Physical Activity Monitors in Children. Obesity. 2002; 10:150-57.

Puyau MR, Adolph AL, Vohra FA, Zakeri I, Butte NF. Prediction of Activity Energy Expenditure Using Accelerometers in Children. Medicine \& Science in Sports \& Exercise. 2004; 36:1625-31. [PubMed: 15354047]

Robertson W, Friede T, Blissett J, Rudolf MCJ, Wallis M, Stewart-Brown S. Pilot of "Families for Health": community-based family intervention for obesity. Archives of Disease in Childhood. 2008; 93:921-28. [PubMed: 18463121]

Schmitz KH, Lytle LA, Phillips GA, Murray DM, Birnbaum AS, Kubik MY. Psychosocial correlates of physical activity and sedentary leisure habits in young adolescents: The teens eating for energy and nutrition at school study. Preventive Medicine. 2002; 34:266-78. [PubMed: 11817924]

Snoek HM, Engels RCME, Janssens JMAM, van Strien T. Parental behaviour and adolescents' emotional eating. Appetite. 2007; 49:223-30. [PubMed: 17391806]

Tilson EC, McBride CM, Brouwer RN. Formative Development of an Intervention to Stop Family Tobacco Use: The Parents and Children Talking (PACT) Intervention. Journal of Health Communication. 2005; 10:491-508. [PubMed: 16203629]

Tran KM, Johnson RK, Soultanakis RP, Matthews DE. In-person vs Telephone-administered Multiplepass 24-hour Recalls in Women: Validation with Doubly Labeled Water. Journal of the American Dietetic Association. 2000; 100:777-83. [PubMed: 10916515]

van den Bos R, de Ridder D. Evolved to satisfy our immediate needs: Self-control and the rewarding properties of food. Appetite. 2006; 47:24-29. [PubMed: 16678304]

Wardle J, Sanderson S, Guthrie CA, Rapoport L, Plomin R. Parental Feeding Style and the Intergenerational Transmission of Obesity Risk. Obesity. 2002; 10:453-62.

West F, Sanders MR, Cleghorn GJ, Davies PSW. Randomised clinical trial of a family-based lifestyle intervention for childhood obesity involving parents as the exclusive agents of change. Behaviour Research and Therapy. 2010; 48:1170-79. [PubMed: 20883981]

Whitaker RC, Wright JA, Pepe MS, Seidel KD, Dietz WH. Predicting Obesity in Young Adulthood from Childhood and Parental Obesity. New England Journal of Medicine. 1997; 337:869-73. [PubMed: 9302300]

Wills TA, Gibbons FX, Gerrard M, Murry VM, Brody GH. Family Communication and Religiosity Related to Substance Use and Sexual Behavior in Early Adolescence: A Test for Pathways Through Self-Control and Prototype Perceptions. Psychology of Addictive Behaviors. 2003; 17:312-23. [PubMed: 14640827]

Wrotniak BH, Epstein LH, Paluch RA, Roemmich JN. Parent Weight Change as a Predictor of Child Weight Change in Family-Based Behavioral Obesity Treatment. Arch Pediatr Adolesc Med. 2004; 158:342-47. [PubMed: 15066873]

Zucker NL, Ferriter C, Best S, Brantley A. Group Parent Training: A Novel Approach for the Treatment of Eating Disorders. Eating Disorders. 2005; 13:391-405. [PubMed: 16864353] 


\section{Highlights}

- We examined 12 month outcomes in KAN-DO, a childhood obesity prevention study.

- The intervention targeted parenting, especially in the mother.

- Instrumental feeding and snacks in front of TV decreased in the intervention arm.

- Trends toward improvement were observed in diet and activity measures.

- Changes observed may ultimately result in improved weight status for the children. 


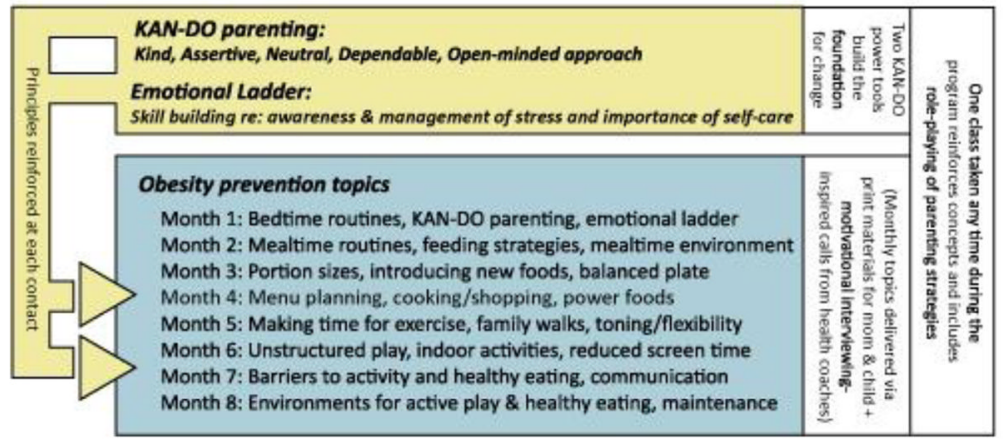

Figure 1.

KAN-DO intervention content

Study conducted in the Triangle and Triad regions of North Carolina, U.S.A. 2007-2011. 


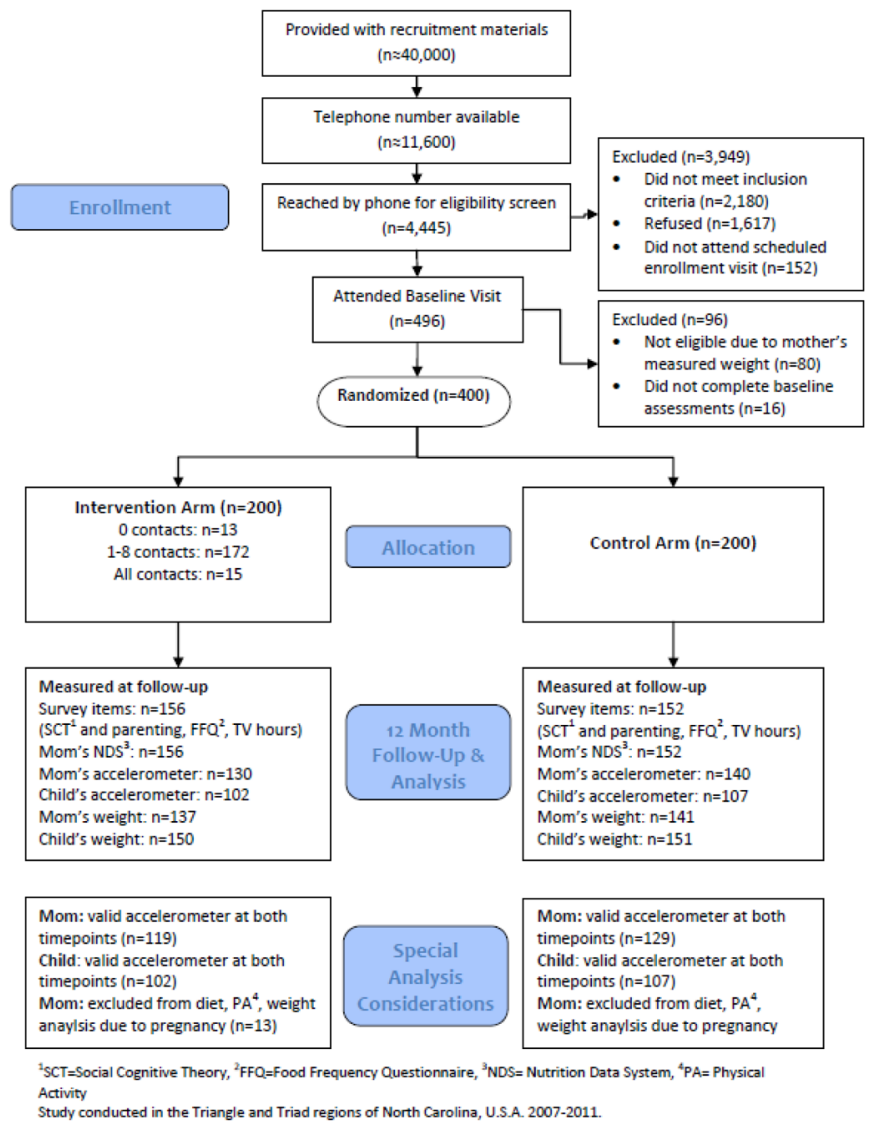

Figure 2.

CONSORT flow diagram

Study conducted in the Triangle and Triad regions of North Carolina, U.S.A. 2007-2011. 
Table 1

Baseline characteristics of mother-child dyads $(n=400)$.

\begin{tabular}{|c|c|c|}
\hline Variable & $\begin{array}{c}\text { Intervention }(\mathbf{n}=\mathbf{2 0 0}) \\
\%(\mathbf{n})\end{array}$ & $\begin{array}{c}\text { Control }(\mathbf{n}=200) \\
\%(n)\end{array}$ \\
\hline \multicolumn{3}{|l|}{ Child: } \\
\hline \multicolumn{3}{|l|}{ Age $($ mean $=3.06 ; \mathrm{SD}=1.0)$} \\
\hline 2 years & $39.0(79)$ & $32.5(65)$ \\
\hline 3 years & $29.5(59)$ & $36.5(73)$ \\
\hline 4 years & $19.0(38)$ & $22.0(44)$ \\
\hline 5 years & $12.5(25)$ & $9.0(18)$ \\
\hline \multicolumn{3}{|l|}{ Sex } \\
\hline Male & $56.5(113)$ & $55.0(110)$ \\
\hline Female & $43.5(87)$ & $45.0(90)$ \\
\hline \multicolumn{3}{|l|}{ Baseline weight status } \\
\hline Underweight & $4.0(8)$ & $1.0(2)$ \\
\hline Normal weight & $71.0(142)$ & $76.0(152)$ \\
\hline$\geq 85^{\text {th }}-<95^{\text {th }}$ percentile & $15.0(30)$ & $15.5(31)$ \\
\hline$\geq 95^{\text {th }}$ percentile & $10.0(20)$ & $7.5(15)$ \\
\hline \multicolumn{3}{|l|}{ Mother: } \\
\hline \multicolumn{3}{|l|}{ Age } \\
\hline$<30$ & $29.5(59)$ & $23.0(46)$ \\
\hline $30-35$ & $31.0(62)$ & $40.5(81)$ \\
\hline$>35$ & $39.5(79)$ & $36.5(73)$ \\
\hline \multicolumn{3}{|l|}{ Race } \\
\hline White & $74.5(149)$ & $76.0(152)$ \\
\hline Black & $21.5(43)$ & $22.0(44)$ \\
\hline Other races & $4.0(8)$ & $2.0(4)$ \\
\hline Hispanic ethnicity & $5.5(11)$ & $4.0(8)$ \\
\hline \multicolumn{3}{|l|}{ Education } \\
\hline High school graduate or less & $9.5(19)$ & $13.5(27)$ \\
\hline Some college & $21.0(42)$ & $19.5(39)$ \\
\hline College degree & $43.0(86)$ & $41.0(82)$ \\
\hline Graduate school & $26.5(53)$ & $26.0(52)$ \\
\hline \multicolumn{3}{|l|}{ Marital status } \\
\hline Single/never married & $10.0(20)$ & $6.5(13)$ \\
\hline Living with a partner & $3.5(7)$ & $4.0(8)$ \\
\hline Married & $86.0(172)$ & $87.0(174)$ \\
\hline Separated/divorced & $0.5(1)$ & $2.5(5)$ \\
\hline \multicolumn{3}{|l|}{ Household income/year } \\
\hline Up to $\$ 15,000$ & $9.7(19)$ & $10.6(21)$ \\
\hline$\$ 15,001-\$ 30,000$ & $7.7(15)$ & $10.1(20)$ \\
\hline$\$ 30,001-\$ 45,000$ & $9.7(19)$ & $8.5(17)$ \\
\hline$\$ 45,001-\$ 60,000$ & $15.9(31)$ & $14.6(29)$ \\
\hline
\end{tabular}

Prev Med. Author manuscript; available in PMC 2013 September 01. 


\begin{tabular}{lcc}
\hline Variable & $\begin{array}{c}\text { Intervention }(\mathbf{n}=\mathbf{2 0 0}) \\
\mathbf{\%}(\mathbf{n})\end{array}$ & $\begin{array}{c}\text { Control }(\mathbf{n}=\mathbf{2 0 0}) \\
\mathbf{\%}(\mathbf{n})\end{array}$ \\
\hline $\begin{array}{l}\text { \$60,001 or more } \\
\text { Parity }\end{array}$ & $56.9(111)$ & $56.3(112)$ \\
$\quad$ Two children & $73.0(146)$ & $63.0(126)$ \\
$\quad$ Three or more & $27.0(54)$ & $37.0(74)$ \\
Study site & & \\
Duke & $67.0(134)$ & $67.5(135)$ \\
UNC-Greensboro & $33.0(66)$ & $32.5(65)$ \\
Baseline BMI (kg/m²) & & \\
Overweight (25-29.9) & $39.5(79)$ & $38.5(77)$ \\
Obese class I (30-34.9) & $35.0(70)$ & $29.0(58)$ \\
Obese class II (35-39.9) & $13.0(26)$ & $21.0(42)$ \\
Obese class III (40+) & $12.5(25)$ & $11.5(23)$ \\
\hline
\end{tabular}

Study conducted in the Triangle and Triad regions of North Carolina, U.S.A. 2007-2011. 


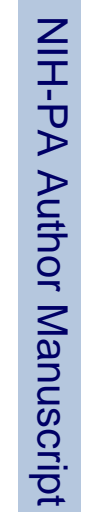

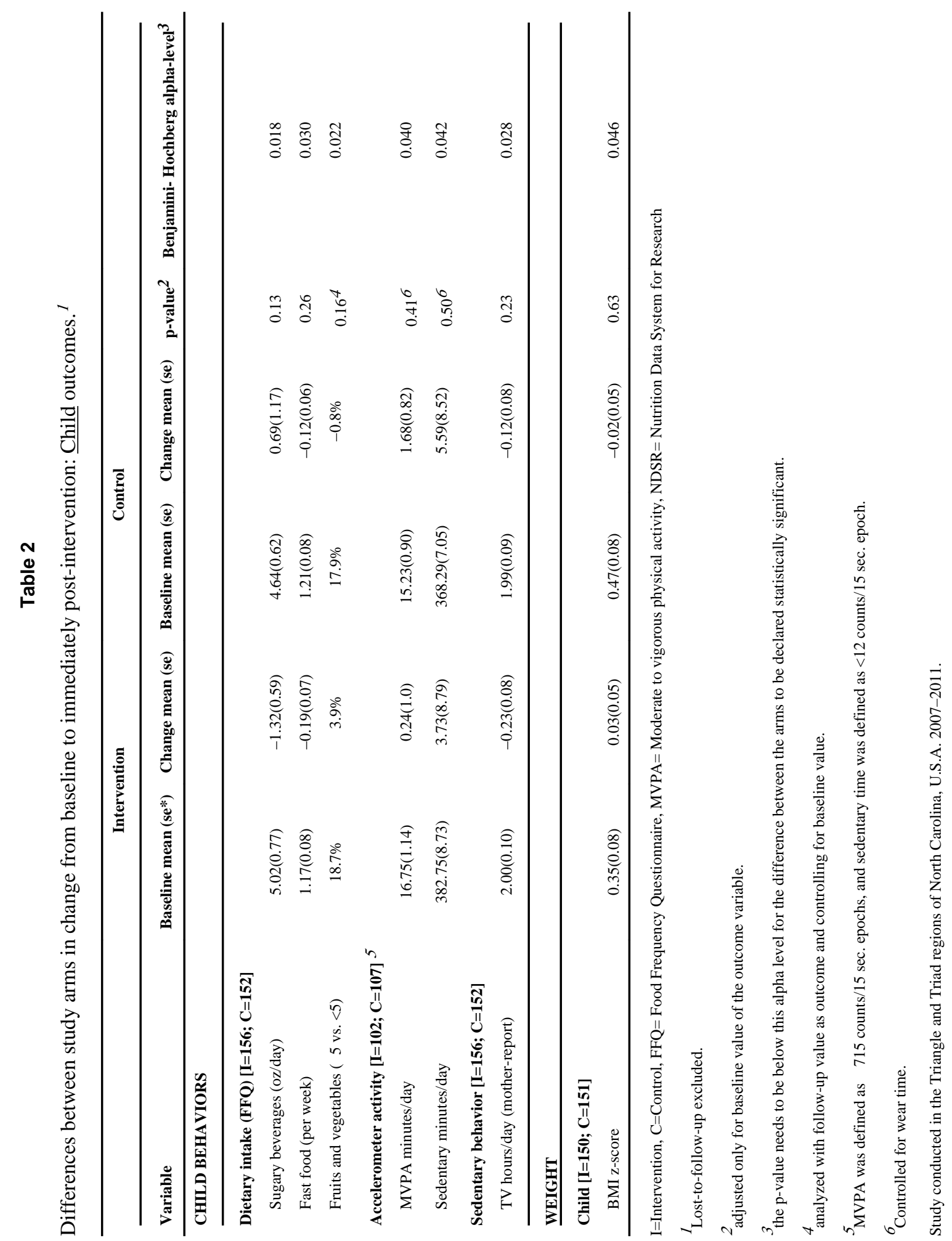

Prev Med. Author manuscript; available in PMC 2013 September 01. 


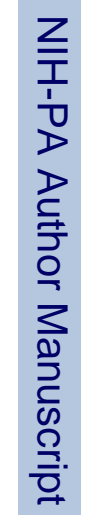

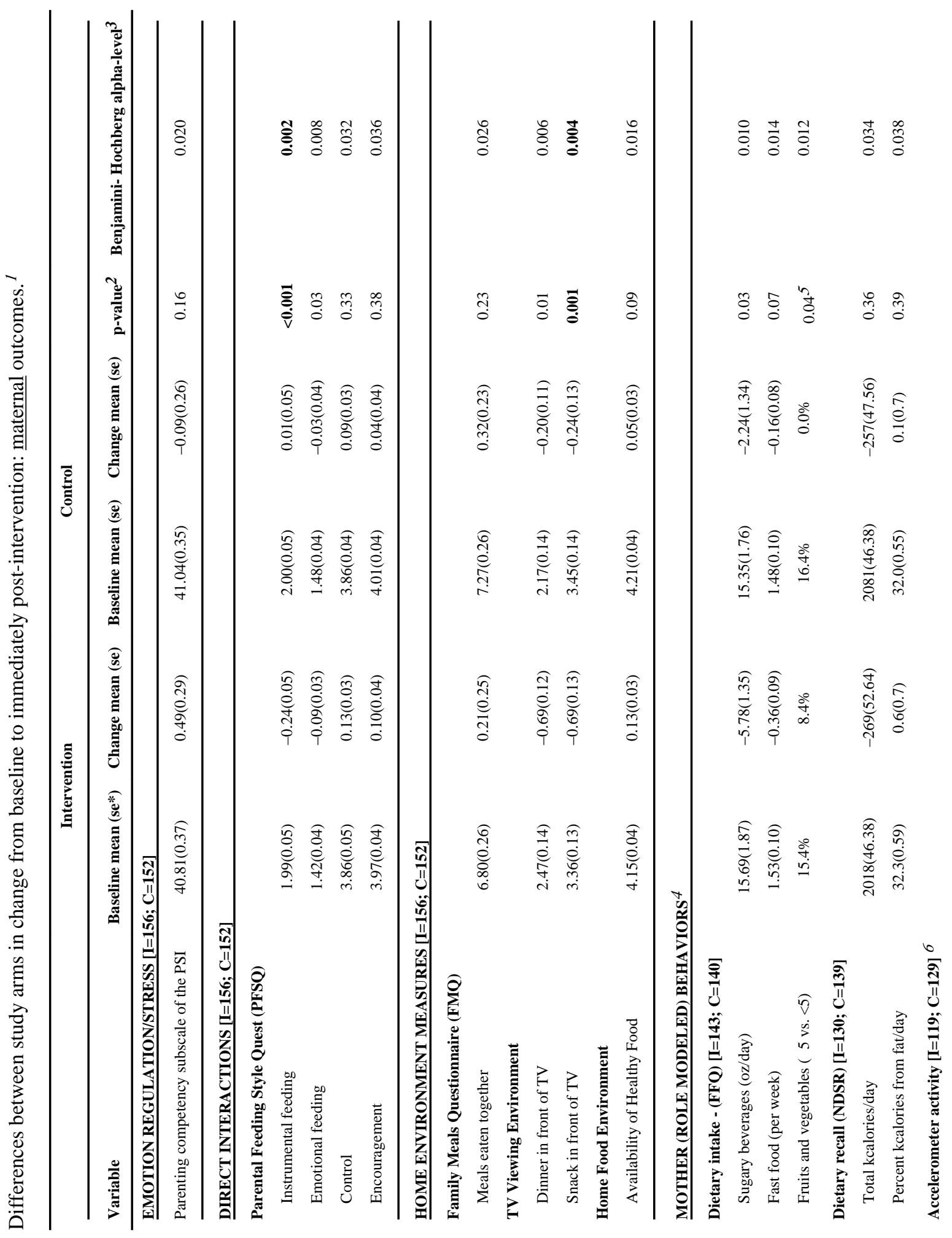




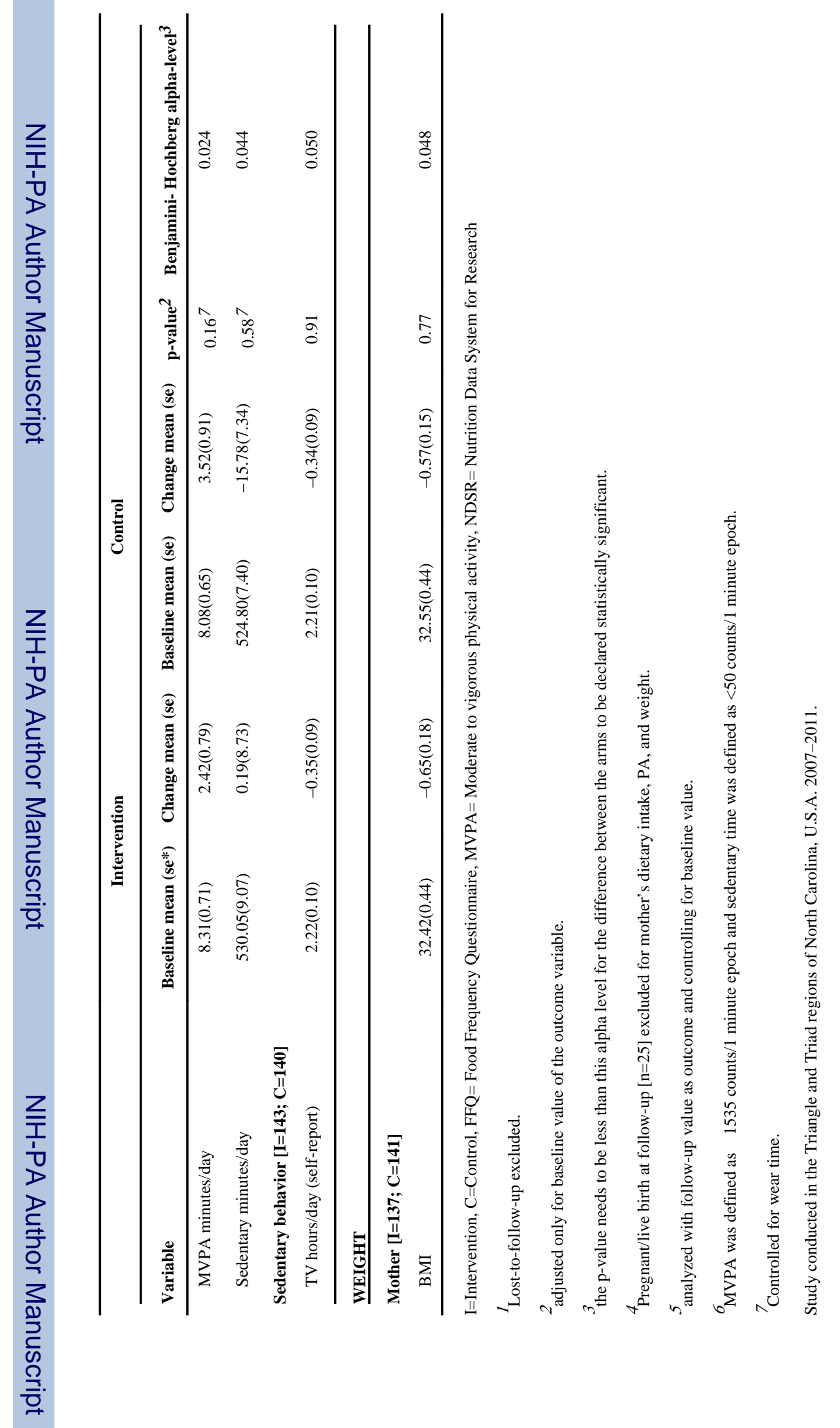

Prev Med. Author manuscript; available in PMC 2013 September 01. 